\title{
Role of the Head of School in Conflict Management in the Industrial 4.0 Revolution
}

\author{
Karimatul Fitriana Dewi \\ Department of Educational Administration \\ Universitas Negeri Malang, Indonesia \\ fitrianado19@gmail.com
}

\author{
Bagus Rachmad Saputra \\ Department of Educational Administration \\ Universitas Negeri Malang, Indonesia \\ bagusrachmad47@gmail.com
}

\author{
Mustiningsih \\ Department of Educational Administration \\ Universitas Negeri Malang, Indonesia \\ mustiningsih.fip@um.ac.id
}

\begin{abstract}
The role of the Principal as a leader in the school as a decision maker in school management will be faced with conditions and problems where the Principal must make the best decisions in the framework of school management to be effective and efficient. Competition between individuals as a component in schools cannot be avoided because each individual has the motivation to work as much as possible and be the best in school management activities. Competition that occurs can lead to conflicts that must be addressed wisely by the Principal as a leader in the school. Conflicts can also be caused by what is expected by all elements in the school not in accordance with the reality that exists in the school. The role of the principal as a leader must be able to direct and take the best decisions in resolving a conflict that occurs in the school. The Principal must be able to understand and implement conflict management so that the conflict in the school becomes an energy, purposive in order to advance the school.
\end{abstract}

Keywords: principal, conflict, conflict management

\section{INTRODUCTION}

School as an educational organization is a collection of several individuals who play an important role in school management activities. School principals, teachers, school administrators, security guards, gardeners, school guards and individuals who are involved in school management are part of the human resource elements owned by the school. Each individual has their own uniqueness and different motivation in the involvement of school management in accordance with their duties. Competition between individuals is a normal and reasonable occur because each individual wanted to show the best performance. It is this competition that causes conflict in schools and inevitably occurs. Individual conflict will also affect the extent to school management. Not to mention when conflicts between individuals will become conflicts between units or parts of the school's organizational structure. Principals as managers and leaders in schools will be confronted with the potential for conflict that can lead to problems.

Principals are required to be able to master and condition conflicts that occur in schools that must be managed properly in which the principal who acts as a manager. Ability and skills possessed by the principal will have an impact on the conditions and situations of conflict in schools is becoming energy positive are able to boost the productivity of all the components that exist in schools to improve the quality school or even become negative that actually affect the performance and conditions that are not harmonious between the components in the school so that it can trigger divisions in school management activities. Social change, technology, and the advancement of science require everyone to change to be better than before and conditions like this are the role of the principal is needed in managing conflicts that occur in schools. The Principal must be able to carry out his role as an organizer, manager, educator, leader, and education supervisor.

Entering the era of the Industrial Revolution 4.0 now, it does not rule out the emergence of increasingly complex educational problems. In this era information technology has become the basis or basis in human life, including in the field of education. In the era of the Industrial Revolution 4.0 several things happened to become infinite through information technology. This era will also disrupt (provide innovation) various human activities, including the fields of science and technology.

Carrying out their role as managers and educational leaders, the principal faces various components that have the potential to cause conflict. This is caused by the heterogeneity of the resources being managed, the large number of interests between units in the overall organizational structure, personnel supporting the implementation of education who have varied backgrounds, interests, tasks, authorities, and responsibilities. Competition between the components, parts or units, interests, goals, needs, increasingly rampant individualism, materialism e exclusive, and others raises the potential for conflict in the institutional life of the school. Not to mention the development of science and technology which also has an impact on social change and unequal growth (Kartono, 1991). Conflicts like these that have to be resolved properly by the principal act as a leader through a conflict management approach.

\section{SOURCES OF CONFLICT}

Conflicts in organizations do not just arise naturally and occur not without cause. And each conflict that arises in an organization is based on different factors depending on how individuals or groups respond to something in their work environment. These factors can come from within and outside the organization. In this 
regard Iswan \& Herwina (2018) suggests a few things to be a source of conflict in the organization, namely: (1) interdependence workflow, each unit in the organization must be managed as a system consisting of interdependent parts that have special functions. But there must still be coordination in terms of division of labor; (2) asymmetry, Conflict due to asymmetry arises due to the existence of individuals with low levels of power needing help, while individuals with higher levels do not respond to these requests. Conflict also arises when individuals with different status values are forced to cooperate with each other in carrying out a task or people with high status are required to interact with people of low status; (3) ambiguity role (role ambiguity or ambiguity domain ) not their considerable guidance regarding the purpose and duties of individuals in the work environment are also potentially lead to conflict. At the group level, this can trigger the ambiguity of domains or jurisdictions, which means that between two groups or more likely to conflict because they do not understand their responsibilities; and (4) scarcity of resources competitiveness of human resources in terms of organization is not a new thing anymore. Individuals tend to do everything they can to keep their position in the organization and that causes conflicts (Zazin, 2010). This is relevant for organizations that are experiencing a setback, and it is rarely found in developing organizations.

\section{CONFLICT MANAGEMENT STRATEGY}

Conflict management strategies are needed to solve conflicts and find solutions in the form of solutions as a form of organizational optimization. The role of the principal in resolving a conflict depends on the view used by the principal in resolving a conflict. This depends on organizational leaders, whether they have traditional, behavioral, or interaction viewpoints in viewing the organization they lead (Soetopo, 2012) Conflicts that occur in schools need to be managed properly by the school principal so that they have the potential to make the organization effective.

Thoha (2011) proposed a general conflict management strategy as follows: (1) a win-lose strategy, (2) a lose-lose strategy, and (3) a win-win strategy. By using the strategy of win-lose, one side wins and one side loses, including the use of authority or power to suppress s a was a party. Could be, the losing party will behave non-productive, less active, and not identify themselves with the goals of the organization. A lose-lose strategy means that all parties to the conflict become losers. This strategy can be in the form of a compromise (both sacrificing their interests), and arbitration (using a third party). Win-win strategy, namely conflict is solved through the method of problem solving or problem solving (Soetopo, 2012).

The school principal as a leader in the school in the face of conflict dap at considering various existing conflict management strategies adapted to the conditions of the conflict at hand. Principals need to think positively in resolving conflicts and conflict management strategies are solutions to help principals resolve conflicts in schools. S ne of things that need attention and the recommended is the start of a passive attitude toward the active orientation, and highly dependent on the level of maturity of the parties in conflict (Soetopo, 2012). The role of the principal needs to have the power to change the behavior of the individual he leads through authority as a leader in the school in order to implement appropriate conflict management strategies in resolving conflicts that occur at school.

The conflict management strategy that can be carried out by principals in the 4.0 era is to maximize services. The intended service is to provide education, understanding of changing times and trying to minimize conflict. Teachers must be given an understanding in the beginning that the current era is far different from their era in the past. So that it takes openness and adjustments to the demands of the times and technology (Prasetyo, 2018). This method is a preventive measure to avoid the possibility of conflicts that arise

\section{PRINCIPLES FOR CONFLICT MANAGEMENT}

There are some principles that can be used by principals a conflict at school. First, treat it naturally and naturally, meaning that conflicts that arise in the administration of education units are as natural and natural. Conflict has now become an inseparable part of the organization. It does not need to be avoided but must be faced by leaders through conflict management. Moreover, therefore the implementation of conflict management needs to be done naturally and naturally as do other fields of management (Soetopo, 2012).

Second, look at conflict as an organizational dynamic. See that an organization without conflict means silence, static, and not achieving the expected progress. However, the existing conflict must be arranged in such a way that the dynamics that occur can really be something positive to produce change while supporting the development and achievement of educational goals (Soetopo, 2012). The principle that demands the role of the principal to see the conflict that occurs is a dynamic change that occurs in the school and must be faced with the right strategy to increase the productivity of human resources involved in school management in order to achieve the goals set by the school.

Third, leadership testing media. Capabilities and leadership possessed by school principals are tested by conflicts that occur in schools. The extent to which the principal is able to manage and make decisions that are considered most appropriate in resolving a conflict and measure the extent of the school's ability to implement conflict management. Leadership is not only tested when bringing members to achieve goals based on mere formal task routines. The leadership concerned will be more tested when faced with conflicts. Through conflict management, he will have reliable leadership to bring the organization wheel dynamically positive in achieving future goals (Soetopo, 2012).

Fourth, high flexibility means that the conflict management strategy used by leaders is flexible. The choice of strategy is very dependent on: (1) the type, material of the conflict, and the source of the cause, (2) the characteristics of the parties to the conflict, (3) the resources owned and supported, (4) the culture of the community and the organizational climate, (5) anticipating the impact of the conflict, and (6) intensity 
and breadth of conflict (Soetopo, 2012). This is what the principal needs to pay attention to as the role of a leader in the school. Resolve conflicts and manage conflicts properly so that school management can be better.

Seeing the era of 4.0 which demands all fastpaced, it is not surprising that conflicts arise within an organization, especially educational institutions. the complexity of an era is followed by the complexity of a problem. addressing existing problems, principals must basically be able to apply the principle of openness. that is, with global communication and information technology all data access can be easily obtained. The principal must be as open as possible about what aspects are monitored by the teacher, what are the evaluation criteria, what sanctions are applied if there are persons who violate them, and others. So that it does not cause misunderstanding between the principal and the teacher.

\section{STEPS IN CONFLICT MANAGEMENT}

The steps in conflict management that must be done by the principal are as follows: (1) planning conflict analysis, this step is intended to define or determine what conflicts arise in the administration of the education unit. Educational leaders can do it at any time when there are indications of conflict. The education leader in this step must be able to determine the source of the cause. Factors that influence it, its types, and the involvement of parties to the conflict (Ontario, 2016; Yahya, 2018). If all of this is clear, finally the actual conflict can be formulated clearly and firmly, (2) conflict evaluation, conflict evaluation is an effort to determine the quality of a conflict that has been formulated. The quality of a conflict can be viewed from two aspects, namely its intensity and breadth. Both are interrelated with each other, (3) Selection of conflict strategies as follows: understand several principles in the implementation of conflict management, based on the principles above, choose between the chosen conflict management strategies, implement the chosen conflict management strategy, evaluate the implementation of conflict management strategies chosen to know its success, the strategy that has been chosen can be maintained if it shows good results, but if the results are not good or not good then it is necessary to choose another strategy in a sustainable manner (Soetopo, 2012).

\section{SUCCESS CRITERIA FOR CONFLICT MANAGEMENT}

Conflict management implemented by the principal in resolving a conflict can be measured by several criteria. Success criteria for conflict management become a benchmark for the success of school principals in managing conflicts properly. Conflict management carried out by managers or leaders can be said to be successful if it meets the following criteria: (1) The ability to plan conflict analysis where good conflict analysis planning must show a description of conflict phenomena, conflict identification, actual conflict formulation clearly and decisively, (2) Ability to evaluate conflicts in which the measure that can be used is the low or high intensity of a conflict, the extent or extent of a conflict, determining the quality of conflict (light / small), medium / large, or large / severe), determination of conflict resolution based on priority, and (3) ability to choose conflict management strategies (Soetopo, 2012).

The principal as a manager sets the criteria above in implementing conflict management so that conflicts that occur can be resolved and have a positive impact on the principal. Success criteria for conflict management can be considered by the principal when they will later change the way or strategy in resolving conflicts. The effectiveness of the principal's ability to resolve a conflict is measured by the criteria for successful conflict management.

\section{THE ROLE OF SCHOOL PRINCIPALS IN CONFLICT MANAGEMENT IN ERA 4.0}

In the era of development of technology and communication as well as rapid changes in the world, it is also possible to influence the implementation of education. One of them is in terms of the organization and management of the educational institution itself. Schools that still apply traditional methods in their implementation have the potential to experience cultural shock, which is the shock of facing a new culture.

In the 4.0 era, the main focus was communication technology, not an easy thing to be adjusted to the habits or habits of teachers who tend not to be tech. Here, the role of the principal is very necessary to be able to provide education to school residents about the era that is currently happening. It aims to not only realize the importance of knowing and understanding technology, but also as an initial step in anticipation so that schools do not experience backwardness and are able to compete professionally.

The education required to able to equip $\mathrm{p}$ e as well as students with 21 st century skills these skills are critical thinking skills in problem solving, creative and innovative, and communication and collaboration skills. not only for students, teachers must also be prepared to face this skill. Then what is the role of teachers in the Industrial Revolution 4.0 era? Teachers must have educational competence, competence in research, digital business, competence in the era of globalization, and interaction in learning.

It must be recognized that 4.0 has a positive effect on education. But we cannot close our eyes that era 4.0 can also have a negative effect on the administration of education, one of which is the increasingly complex problems of education. Principals certainly cannot limit the absorption of information technology that enters schools so the filter itself must come from the school community, especially the teacher as a messenger and role model for students (Ontario, 2016).

When the principal is confronted with the existing conflict, the readiness and decisions taken are very influential in the process of providing education. Principals, as managers and leaders, must be able to empower the teaching staff and education staff in the school to jointly achieve the vision and mission. What are the problems that arise due to the rapid pace of technology? Here's the problem: (1) competing world is getting tight. This is a homework for the principal to ensure that the output produced by the school is able to compete with the others; (2) freedom of expression of freedom. Although freedom of expression and opinion are 
guaranteed by the law, it does not mean that we are free to express opinions without filtering first. This case often befalls teachers and students in schools and sometimes becomes a boomerang for the school; (3) human power is replaced by digital or machine power; and (4) supervision tends to be not strict because the data can be manipulated (Prasetyo, 2018; Yahya, 2018).

Of the four examples of problems above, which we often encounter at school are number 2 and number 4 . Teachers who are new to technology feel curious and want to try new things such as uploading statuses, photos, videos that have the potential to cause conflict. These activities are usually carried out on the basis of ignorance or even there are some persons who knowingly know this is not justified but deliberately do it. For example, such as uploading status that contains SARA, insults, and uploading pornographic photos or videos. The second problem is that of teacher order which is fading due to the rapid pace of technology. Fingerprint technology is not the only solution to improve the level of teacher discipline. there were many cases found after the teacher did attendance at the fingerprint, he did not enter the class to carry out his work. This was done because he assumed that by taking attendance at the fingerprint he had been registered and did not need to carry out learning in the classroom (Tua \& Gaol, 2018).

\section{EVALUATION PROCEDURES FOR KNOWING THE SUCCESS OF CONFLICT MANAGEMENT}

Measuring the success of conflict management applied must go through a structured evaluation process. The evaluation function in conflict management applied by the principal is not a matter of right or wrong and is successful or not but to what extent the conflict management strategy implemented by the principal is effective in resolving a conflict and having a positive impact on school management. The procedures for evaluating the success of conflict management include: (1) evaluation planning, (2) implementation of the evaluation, and (3) drawing conclusions. The three procedures in knowing the success of conflict management need to be done in a structured manner (Pasathang, Tesaputa, \& Sataphonwong, 2016; Schneider, M., \& Buckley, 2002). The expectation of the evaluation is that there is a change in the principal's strategy in resolving conflicts and what are the obstacles in resolving a conflict and found the right way or strategy to resolve a conflict in school. Evaluation really has a positive impact, so it must be done according to the procedure rather than just assessing conflict management applied by the school principal (Soetopo, 2012).

\section{CONCLUSION}

Conflict in an educational organization that is school cannot be avoided. School as an organization must consist of several groups of individuals who are different and unique as a boundary as a human being and the school will never be separated from problems arising from differences in views or technical and non-technical matters relating to school management. An education manager must be able to manage conflict properly so that conflict becomes a dynamic that brings positive change to school management. The principal must have a broad view of conflict and how to manage a conflict that occurs in the school appropriately through the implementation of conflict management.

The principal must maximize all the potential that exists in the school to properly regulate the resolution of conflicts that occur in schools. The conflict management strategy chosen by the principal must be precise and fast in accordance with the conflict being faced. School principals must carry out the principles of conflict management, steps in conflict management, criteria for success in conflict management, and procedures for knowing the success of conflict management. The ability of a school principal as a manager and leader in a school will be tested by conflicts that occur in the school, therefore a school principal must be capable and have extensive insight into conflict management.

\section{REFERENCES}

[1] Iswan \& Herwina. (2018). Strengthening Islamic Perspective Character Education in the Millennial Era IR 4.0. Proceedings of the National Seminar: Building Synergy in Strengthening Character Education in Era 4.0. Jakarta: Muhammadiyah University Jakarta.

[2] Ontario. (2016). 21 Century Competencies: Toward defining 21 Century Competencies. Retrieved July 25, 2019 ,

from

www.ksbe.edu/assets/spi/pdfs/21centuryskillsfull.pdf.

[3] Pasathang, S., Tesaputa, K., \& Sataphonwong, P. (2016). Teachers' Performance Motivation System in Thai Primary Schools. International Education Studies, 9(7), 119-129.

[4] Prasetyo, B., and T. (2018). Industrial Revolution 4.0 and the Challenges of Social Change. SEMATEXSOS Proceedings 3 National Development Strategy Facing the Industrial Revolution 4.0.

[5] Schneider, M., \& Buckley, J. (2002). What Do Parents Want from Schools? Evidence from the internet. Educational Evaluation and Policy Analysis, 24(2), 133144.

[6] Soetopo, H. (2012). Organizational Behavior: Theory and Practice in the Field of Education. Bandung: Rosdakarya.

[7] Thoha, M. (2011). Organizational Behavior: Basic Concepts and Their Applications. Jakarta: Raja GrafindoPersada.

[8] Tua, N., \& Gaol, L. (2018). The Role of the Principal in Improving Teacher Performance. New York: Penguin.

[9] Yahya, M. (2018). Industrial Era 4.0: Challenges and Opportunities for the Development of Indonesian Vocational Education. Speech inauguration of Professor Position. Makassar: Makassar State University.

[10] Zazin, N. (2010). Conflict Leadership \& Management: Strategies for Managing Conflict in Organizational Innovation and Education in Madrasas or Superior Schools. Yogyakarta: Absolute Media. 